\title{
2,4,5-Trimethoxyldalbergiquinol promotes osteoblastic differentiation and mineralization via the BMP and Wnt/ $\beta$-catenin pathway
}

\author{
H-M Yun ${ }^{1}$, K-R Park ${ }^{1}$, TH Quang ${ }^{2}$, H Oh², JT Hong ${ }^{3}$, Y-C Kim² and E-C Kim ${ }^{*, 1}$
}

Dalbergia odorifera has been traditionally used as a medicine to treat many diseases. However, the role of 2,4,5trimethoxyldalbergiquinol (TMDQ) isolated and extracted from $D$. odorifera in osteoblast function and the underlying molecular mechanisms remain poorly understood. The aim of this study was to investigate the effects and possible underlying mechanisms of TMDQ on osteoblastic differentiation of primary cultures of mouse osteoblasts as an in vitro assay system. TMDQ stimulated osteoblastic differentiation, as assessed by the alkaline phosphatase (ALP) activity, ALP staining, mineralized nodule formation, and the levels of mRNAs encoding the bone differentiation markers, including ALP, bone sialoprotein (BSP), osteopontin, and osteocalcin. TMDQ upregulated the expression of Bmp2 and Bmp4 genes, and increased the protein level of phospho-Smad1/5/8. Furthermore, TMDQ treatment showed the increased mRNA expression of Wnt ligands, phosphorylation of GSK3, and the expression of $\beta$-catenin protein. The TMDQ-induced osteogenic effects were abolished by Wnt inhibitor, Dickkopf-1 (DKK1), and bone morphogenetic protein (BMP) antagonist, noggin. TMDQ-induced runt-related transcription factor 2 (Runx2) expression was attenuatted by noggin and DKK1. These data suggest that TMDQ acts through the activation of BMP, Wnt $/ \beta$-catenin, and Runx2 signaling to promote osteoblast differentiation, and we demonstrate that TMDQ could be a potential agent for the treatment of bone loss-associated diseases such as osteoporosis.

Cell Death and Disease (2015) 6, e1819; doi:10.1038/cddis.2015.185; published online 16 July 2015

Osteoporosis, the most common bone disease, is a remodeling disease characterized by decreased bone mass, increased bone fragility, and increased risk of fractures. ${ }^{1}$ Potent anticatabolic drugs that include estrogen, bisphosphonates, and RANKL-inhibitor have been the main therapies for osteoporosis. ${ }^{2}$ Furthermore, anti-resorptives have only modest effects on increasing bone mass. ${ }^{3}$ However, the FDA-approved anabolic agent parathyroid hormone has limited use because it is comparatively expensive and difficult to administer. ${ }^{4}$ Thus, it would be most helpful to develop the new and effective anabolic agents that directly stimulate bone formation.

Dalbergia odorifera, a traditional herbal medicine in East Asia, has been used to treat various diseases including blood disorders, swelling, ischemia, necrosis, and rheumatic pain. ${ }^{5}$ Previous phytochemical studies reported that the isolated phenolic compounds of $D$. odorifera such as isoflavanones, isoflavans, neoflavonoids, and chalcones exert various beneficial properties, such as anti-oxidant, anti-microbial, and anti-inflammatory effects. ${ }^{5-10}$ We previously reported that 4,2',5'-trihydroxy-4'-methoxychalcone, a biologically active chalcone isolated from the heartwood of $D$. odorifera, exhibited protective effects against glutamate-induced oxidative injury in HT22 cells. ${ }^{10}$ In addition, we demonstrated that 4,2',5'-trihydroxy-4'-methoxychalcone exhibits antiinflammatory properties by inducing heme oxygenase-1 in murine macrophages. ${ }^{11}$

Although we isolated and identified novel compound 2,4,5-trimethoxyldalbergiquinol (TMDQ) compound from the heartwood of $D$. odorifera, its pharmacological effects in bone-forming cells have not been defined yet. The aim of this work was to investigate the effects and its underlying signal mechanism of TMDQ on osteoblastic differentiation in primary culture of mouse calvarial osteoblasts as an in vitro assay system.

\section{Results}

TMDQ increases osteoblastic differentiation in primary culture of mouse calvarial osteoblasts. To determine the cytotoxic potential of TMDQ, its effect on viability of the osteoblasts was evaluated. Up to a concentration of $10 \mu \mathrm{M}$, no cytotoxic effects could be observed using 3-[4,5dimethylthiazol-2-yl]-2,5-diphenyltetrazolium bromide (MTT)

\footnotetext{
${ }^{1}$ Department of Oral and Maxillofacial Pathology, School of Dentistry and Research Center for Tooth and Periodontal Regeneration (MRC), Kyung Hee University, Seoul 130-701, Republic of Korea; ${ }^{2}$ Department of Pharmacy, Institute of Pharmaceutical Research and Development, College of Pharmacy, Wonkwang University, Iksan 570749, Korea and ${ }^{3}$ Department of Pharmacy, College of Pharmacy and Medical Research Center, Chungbuk National University, 12 Gaesin-dong, Heungduk-gu, Cheongju 361-763, Korea

${ }^{*}$ Corresponding author: E-C Kim, Department of Oral and Maxillofacial Pathology, School of Dentistry and Research Center for Tooth and Periodontal Regeneration (MRC), Kyung Hee University, 1 Heogi-Dong, Dongdaemun-Gu, Seoul 130-701, Republic of Korea. Tel: +82 2961 0746; Fax: +82 2960 1457; E-mail: eckim@khu.ac.kr Abbreviations: ALP, alkaline phosphatase; BMP, bone morphogenetic protein; BSP, bone sialoprotein; DKK1, Dickkopf-1; MAPK, mitogen-activated protein kinase; OCN, osteocalcin; Runx2, runt-related transcription factor 2; TMDQ, 2,4,5-trimethoxyldalbergiquinol; OPN, osteopontin; OS, osteogenic supplement; RT-PCR reverse transcriptase-PCR

Received 16.3.15; revised 20.5.15; accepted 28.5.15; Edited by M Agostini
} 
a<smiles>C=CC(c1ccccc1)c1cc(OC)c(OC)cc1OC</smiles>

C

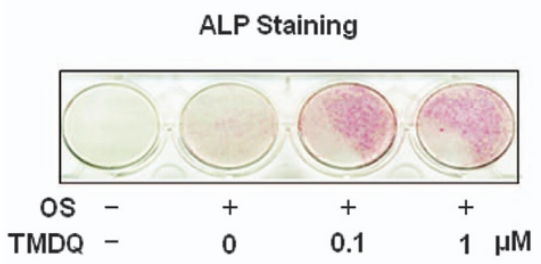

e

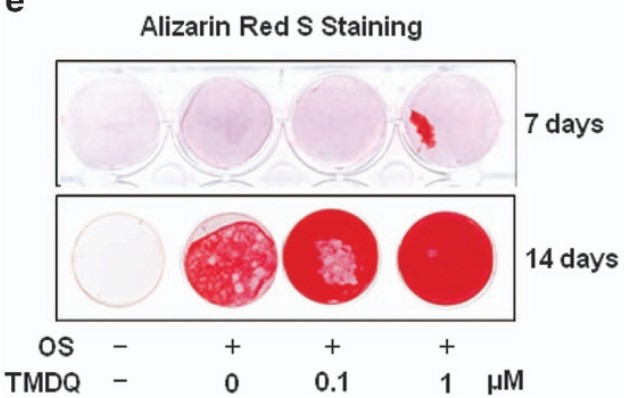

b

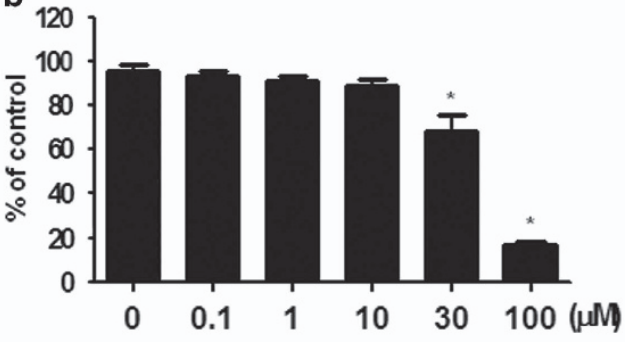

d

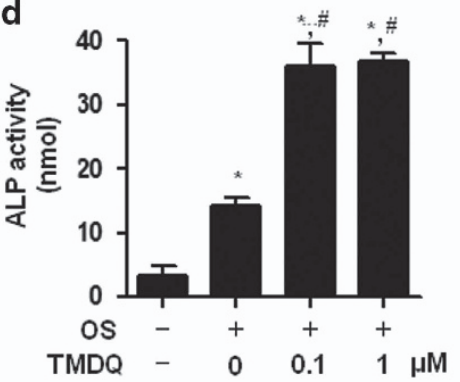

f

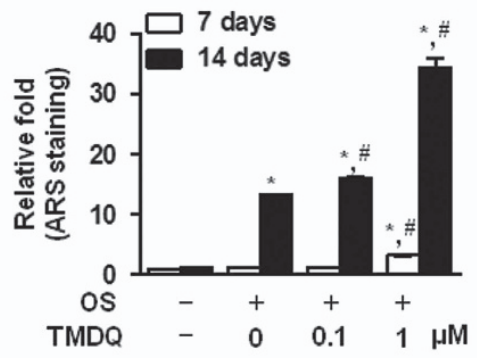

Figure 1 Effects of 2,4,5-trimethoxyldalbergiquinol (TMDQ) on cytotoxicity and osteoblastic differentiation in primary culture of mouse calvarial osteoblasts. (a) Chemical structures of TMDQ. (b) Cell viability was determined using the MTT assay. (c-f) Differentiation was assessed by ALP activity (d), ALP staining (c), and Alizarin red staining (e). The intensity of Alizarin red staining was determined by optical density (f). Cells were treated with osteogenic supplement medium (OS) containing $50 \mu \mathrm{g} / \mathrm{ml} \mathrm{L}$-ascorbic acid and $10 \mathrm{mM} \beta$-glycerophosphate with indicated concentration of TMDQ for 1 day (b), 5 days (c and $\mathbf{d}), 7$ and 14 days (e and $\mathbf{f}$ ). ${ }^{*} P<0.05$, versus control. ${ }^{\#} P<0.05$, versus 0 S. The data presented are representative of three independent experiments

assay (Figure 1b). To investigate the effects of TMDQ on osteoblastic differentition in the osteoblasts, cells were treated with osteogenic supplement (OS) medium in the presence or absence of TMDQ at non-cytotoxic concentrations $(0.1-1 \mu \mathrm{M})$. The effect of TMDQ on osteoblastic differentiation was first assessed by measuring the ALP activity as an early phase marker in the osteoblasts. As shown in Figure 1d, TMDQ increased the ALP activity at concentrations ranging from 0.1 to $1 \mu \mathrm{M}$. Under the same conditions, the effect of TMDQ on ALP activity was also visualized by ALP staining. As shown in Figure 1c, ALP staining was consistent with ALP activity. The degree of mineralization was determined by Alizarin red staining as a late phase marker. Consistent with the effects on ALP activity and ALP staining, TMDQ increased mineralization by Alizarin red staining (Figure 1e). The quantification of Alizarin red staining showed significant stimulatory effect of TMDQ in a concentration-dependent manner (Figure 2f). As TMDQ significantly increased early and late maker for differentiation in the osteoblasts (Figure 2), we further investigated their effects on mRNA expression for osteoblast-specific genes.
As shown in Figure 2, TMDQ also upregulated ALP, osteocalcin (OCN), bone siaophosphoprotein (BSP), and osteopontin (OPN) mRNA expression.

TMDQ activates bone morphogenetic protein (BMP) and $W n t / \beta$-catenin signaling but not MAPKs signaling. To understand the signal pathways involved in the regulation of cell differentiation by TMDQ, mitogen-activated protein kinase (MAPK), BMPs, and Wnt/ $\beta$-catenin pathways were analyzed via reverse transcriptase-PCR (RT-PCR), real-time PCR, western blot analysis, and immunofluorescence. As shown in Figure 3a, the treatment of osteoblasts with TMDQ for $30 \mathrm{~min}$ did not affect the phosphorylation of ERK1/2, JNK, and p38 MAPK.

As BMP pathway has been shown to play an important role in osteoblastic differentiation, ${ }^{12,13}$ we examined the effect of TMDQ on Bmp expression and BMP signaling. We found that TMDQ enhanced Bmp2 and Bmp4 mRNA expression as well as the downstream signaling molecules of BMP, and the phosphorylation of Smad1/5/8 in the osteoblasts (Figures $3 b-d$ ). To determine whether TMDQ 

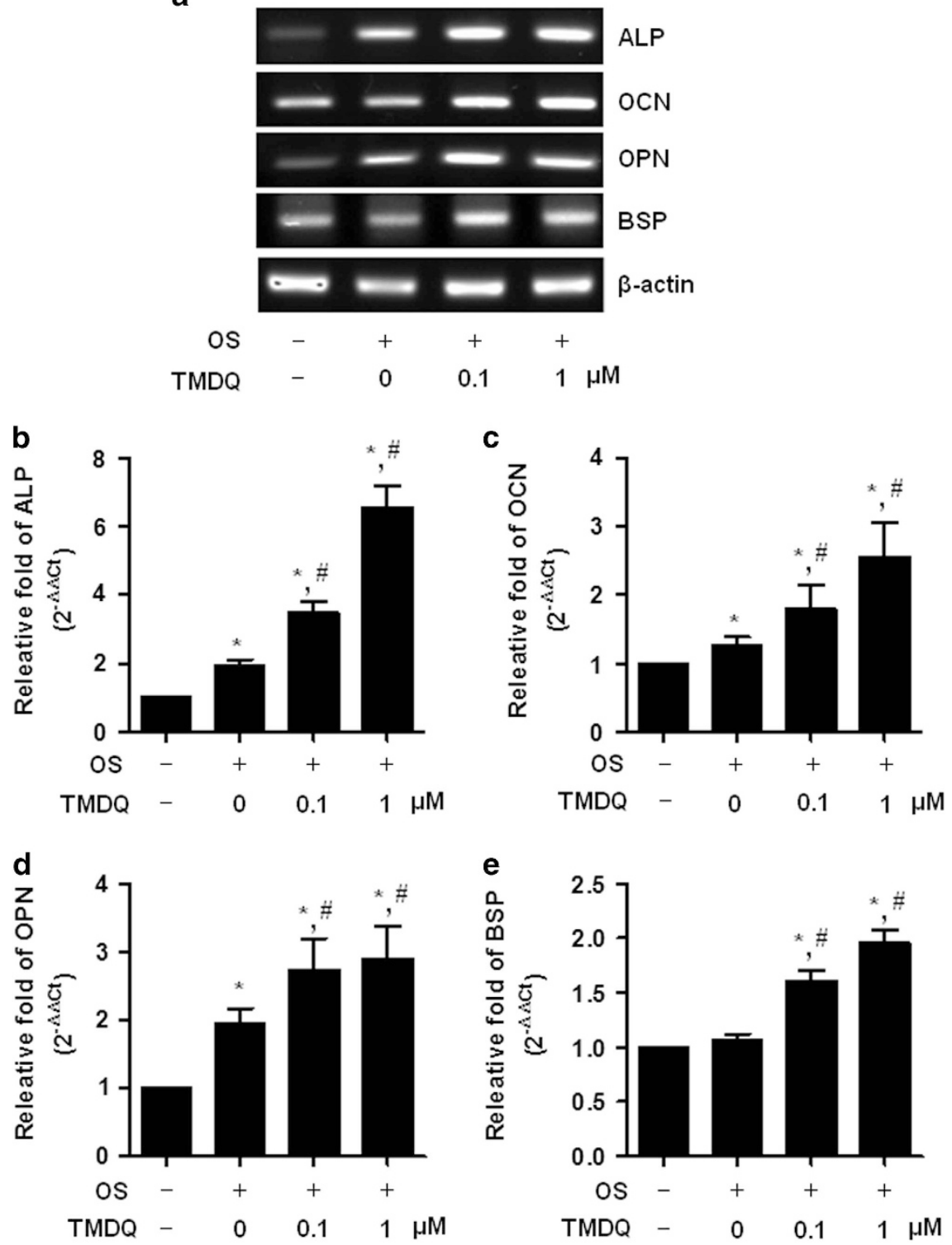

Figure 2 Effects of TMDQ on the mRNA expression of bone matrix proteins in the osteoblasts. (a) Cells were cultured in OS with indicated concentration of TMDQ for 7 days. Total RNA was isolated and analyzed by RT-PCR. (b-e) The level of the target gene expression was determined by real-time PCR, and the values obtained for the target gene expression were normalized to $\beta$-actin and relatively quantified to the expression in non-stimulated control cells. ${ }^{*} P<0.05$, versus control. ${ }^{\#} P<0.05$, versus OS. The data presented are representative of three independent experiments

affects $W n t / \beta$-catenin signaling, we examined the effects of TMDQ on the mRNA expression of Wnt ligands, the phosphorylation of GSK3, and the expression of $\beta$-catenin protein. The osteoblasts treated with TMDQ showed the upregulation of Wnt1 and Wnt3a mRNA and phosphorylation of GSK3, but did not affect the expression of Wnt5a mRNA (Figures 3b, c and e). Likewise, the protein levels of total $\beta$-catenin $(\mathrm{T})$ and nuclear $\beta$-catenin $(\mathrm{N})$ in the osteoblasts were increased by treatment with TMDQ (Figures $3 f$ and $g$ ). To confirm the phosphorylation of Smad1/5/8 and the nuclear translocation of $\beta$-catenin after the treatment with TMDQ, immunofluorescence staining was carried out. Immunocytochemical observation of
TMDQ-treated osteoblasts revealed the rapid nuclear translocation of $\mathrm{p}$-Smad1/5/8 and $\beta$-catenin (Figure 4).

TMDQ causes osteoblastic differentiation via the BMPs and $\mathbf{W n t} / \beta$-catenin signaling pathway. To further investigate whether TMDQ induced osteoblastic differentiation through the activation of the BMP and $W n t / \beta$-catenin signaling pathway, cells were pretreated with Wnt inhibitor, Dickkopf-1 (DKK1), and BMP antagonist, noggin, for $1 \mathrm{~h}$ before treatment with TMDQ. Results showed that noggin pretreatment drastically inhibited TMDQ-mediated ALP staining, ALP activity, and mineralized nodule formation, whereas DKK1 partially attenuated (Figure 5). 
a

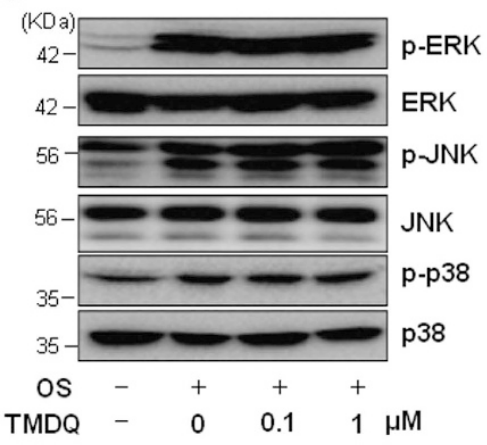

b

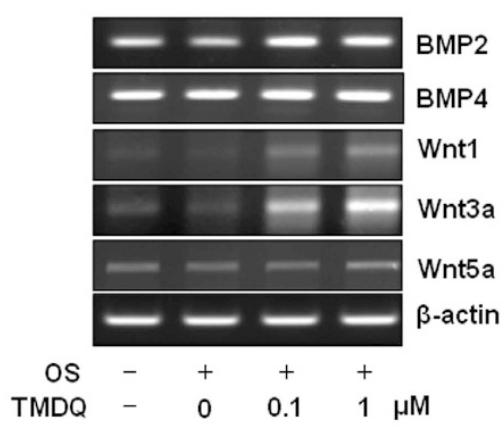

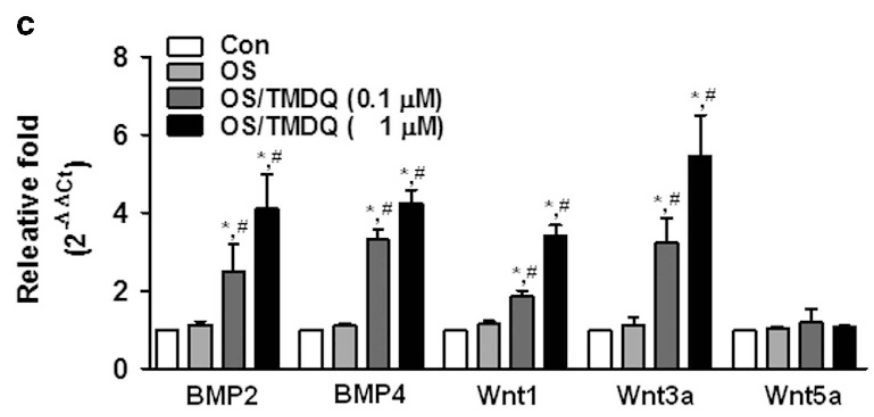

d

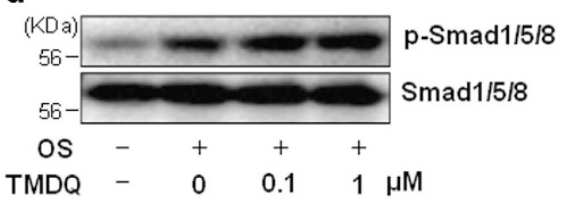

f

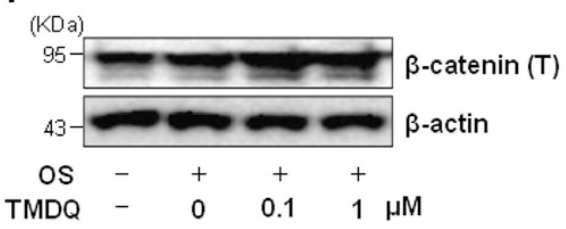

e

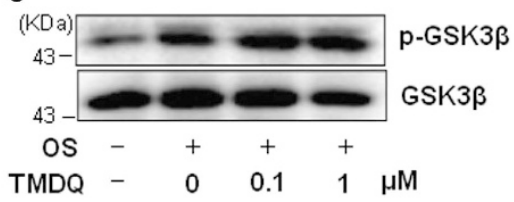

g

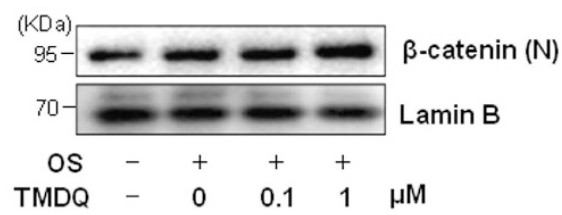

Figure 3 Effects of TMDQ on the activation of MAP kinases, BMP, and Wnt signaling in the osteoblasts. (a-g) Cells were cultured in OS with indicated concentration of TMDQ for $30 \mathrm{~min}(\mathbf{a})$ and 2 days $(\mathbf{b}-\mathbf{g})$. mRNA and protein expression levels were assessed by RT-PCR (b), real-time PCR (c), and western blot analysis (d-g), respectively. T: total, N: nuclear. The results are representative of three independent experiments

To examine the link between the activation of the BMP and $\mathrm{Wnt} / \beta$-catenin pathways, we investigated the effects of TMDQ on $\beta$-catenin downstream target gene, runt-related transcription factor 2 (Runx2), which is a key transcription factor that has an essential role in osteoblastic differentiation. ${ }^{14}$ The expression of Runx2 was significantly increased by TMDQ after $48 \mathrm{~h}$ incubation (Figure 6a). In addition, DKK1 and noggin attenuated TMDQ-stimulated Runx2 protein expression (Figure 6b). To further validate the observation with a genomic approach, the osteoblasts were treated with TMDQ in the presence of Runx2 siRNA to directly downregulate Runx2, as well as its upstream targets, Samd4 siRNA (a final molecule of BMP2-Samd1/5/8 pathway) and TCF1 siRNA (a final molecule of Wnt/beta-catenin pathway). As shown in Figure 6c, Runx2, Smad4, and TCF1 siRNAs attenuated the TMDQ-induced ALP activity. Thus, our pharmacological and genomic approaches suggest that the BMP and $\mathrm{Wnt} / \beta$-catenin pathways are required for TMDQ-mediated osteoblastic differentiation.

\section{Discussion}

Osteoblastic differentiation is a crucial aspect of bone formation and remodeling, which is a process that is severely compromised in osteoporosis. For in vitro studies, osteoblasts isolated from calvaria of newborn animals were widely used for osteoblastic differentiation because of relatively pure population. ${ }^{15}$ In the present study, we used primary cultures of mouse calvarial osteoblasts isolated from newborns as an in vitro assay system for osteoblastic differentiation. Recently, we reported that 6,4'-dihydroxy-7-methoxyflavanone and 9-hydroxy-6,7-dimethoxydalbergiquinol isolated from $D$. odorifera inhibit osteoclast differentiation and their 
a
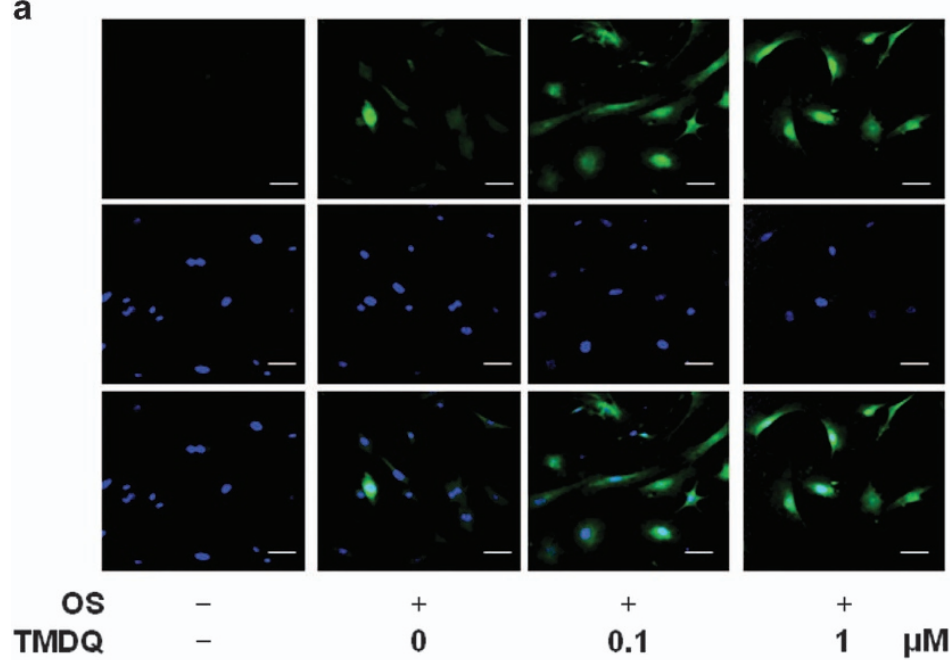

pSmad1/5/8
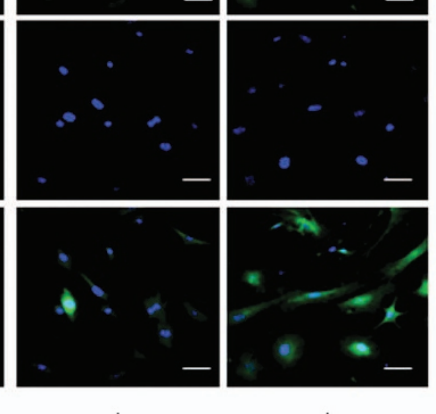

$+$

0

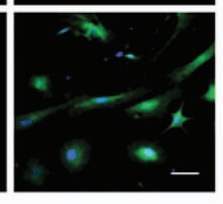

$+$

0.1

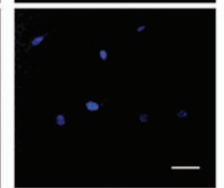

DAPI

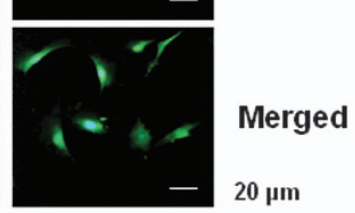

b
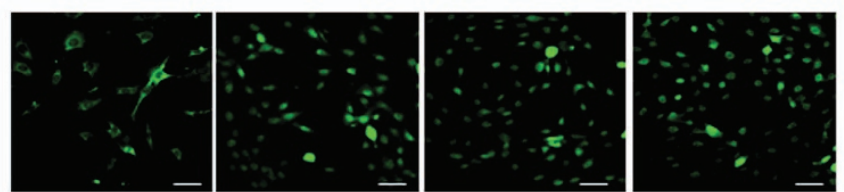

$\beta$-catenin
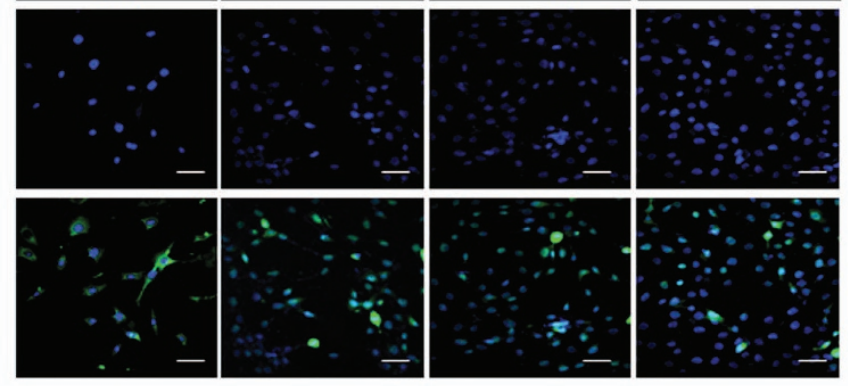

DAPI
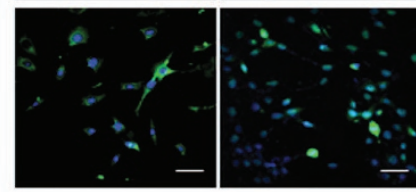

OS

TMDQ

$+$

0.1

.

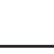


a

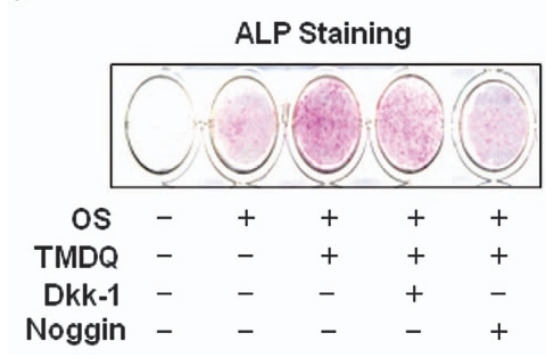

c

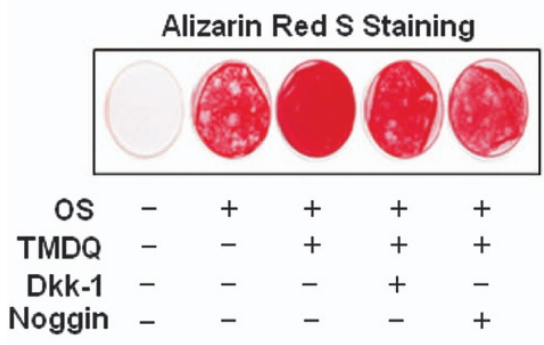

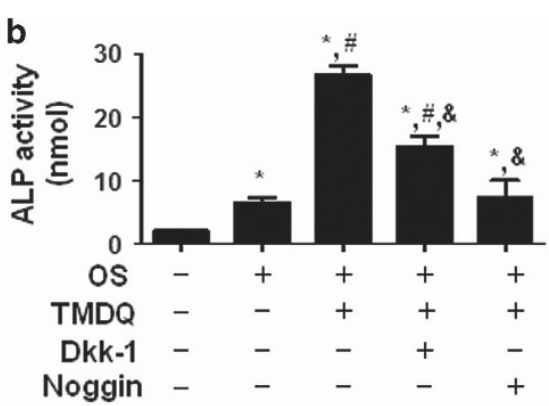

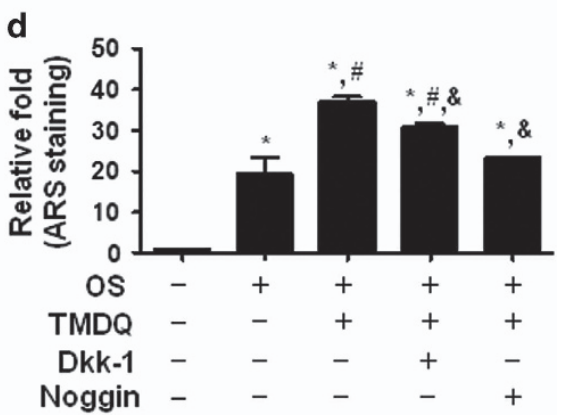

Figure 5 Effects of the inhibition of BMP and Wnt signaling pathway on TMDQ-induced osetoblastic differentiation in the osteoblasts. (a-d) Cells were pretreated with noggin $(10 \mu \mathrm{g} / \mathrm{ml})$ or DKK1 $(0.5 \mu \mathrm{g} / \mathrm{ml})$ for $1 \mathrm{~h}$, and then cultured in OS with TMDQ for 5 (a and $\mathbf{b})$ and 14 days (c and $\mathbf{d})$. ALP activity was measured via ALP staining (a) and ALP activity (b). Mineralized nodule formation was assessed by Alizarin red staining (c), and stains were eluted and measured at $590 \mathrm{~nm}$. The data are represented as relative fold of the control (d). ${ }^{*} P<0.05$, versus control. ${ }^{\#} P<0.05$, versus OS. ${ }^{\&} P<0.05$, versus TMDQ. Data are representative of three independent experiments

TMDQ-mediated osteoblastic differentiation. MAP kinases signaling (ERK1/2, p38, and JNK1/2) also represents as an alternative and non-canonical pathway for BMP2 signal transduction to promote osteogenic factors including Runx2. 25,26 However, TMDQ did not affect MAP kinases signaling in the osteoblasts. These data suggest that TMDQ promotes osteoblastic differentiation through the BMP/Smad pathway but not the MAPKs pathway.

$W n t / \beta$-catenin signaling has critical roles in the bone formation. ${ }^{27}$ In vitro and in vivo studies showed that the activation of $\mathrm{Wnt} / \beta$-catenin signaling promotes osteoblastic differentiation and mineralization, whereas it inhibits apoptosis in osteoblasts and osteocyte. ${ }^{19,24,28,29}$ The Wnt ligands bind to Frizzled and LRP5/6 receptors, and induce the stabilization of cytoplasmic $\beta$-catenin by inhibiting GSK3 $\beta .{ }^{30}$ Consequently, the $\beta$-catenin was accumulated in the cytoplasm and translocated into the nucleus to regulate gene expression. ${ }^{31,32}$ In the present study, we demonstrated that TMDQ significantly increased the expression of canonical Wnt ligands and stabilized the $\beta$-catenin by inactivating GSK3 $\beta$, allowing the stabilization and nuclear translocation of $\beta$-catenin. Moreover, the TMDQ-induced osteogenic effects were abolished by Wnt inhibitor, DKK1. These results suggest that TMDQ promotes osteoblastic differentiation and mineralization through the activation of the BMP and $\mathrm{Wnt} / \beta$-catenin signaling pathways.

Runx2 is the main transcription factor required for the activation of osteoblastic differentiation and is crucial for the regulation of genes responsible for the production of bonespecific proteins. ${ }^{33}$ BMP2-mediated Runx2 expression has an important role in the osteoblastic differentiation. ${ }^{34,35}$ In the present study, the protein level of Runx2 was significantly increased in the TMDQ-treated osteoblasts. In addition, the pharmacological and genomic downregulation for Runx2 attenuated TMDQ-mediated osteoblastic differentiation. It was reported that $\mathrm{Wnt} / \beta$-catenin signaling increases BMP2 expression and vice versa, ${ }^{36,37}$ as well as osteogenic genes including Runx2 integrate the BMP2 and Wnt/ $\beta$-catenin signaling pathways in the regulation of osteoblastic differentiation. ${ }^{37-41}$ Based on the above results and the upregulation of Runx2 by TMDQ, Runx2 is activated by the BMP-and Wnt/ $\beta$-catenin-dependent signaling pathways in the osteoblasts, suggesting functional cross talk between BMP2 and $\mathrm{Wnt} / \beta$-catenin siganaling.

In summary, the present study is the first report that TMDQ promotes osteoblastic differentiation through the BMP and Wnt/ $\beta$-catenin signaling pathway to activate Runx2 in primary cultures of mouse calvarial osteoblasts. These findings suggest that TMDQ may be useful in inducing osteogenesis and facilitating bone mineralization for bone diseases such as osteoporosis.

\section{Materials and Methods}

Isolation and identification of 2,4,5-trimethoxydalbergiquinol. Dried heartwoods of $D$. odorifera $(1.65 \mathrm{~kg})$ were extracted with EtOH by untrasonics for $1 \mathrm{~h}$. After concentrated in vacuo, the EtOH extract $(200 \mathrm{~g})$ was suspended in $\mathrm{H}_{2} \mathrm{O}$ and partitioned with EtOAc to give EtOAc (DOE, $180 \mathrm{~g}$ ) and aqueous fractions. Fraction DOE was chromatographed over a silica gel column, eluting with acetone in $n$-hexane (5-50\%, step-wise) and washing with $\mathrm{MeOH}$ to provide seven subfractions (DOE1-6). Subfraction DOE3 was separated by a silica gel column chromatography, eluting with $n$-hexane- $\mathrm{CH}_{2} \mathrm{Cl}_{2}(1: 2)$ to give five subfractions (DOE31-5). Subfraction DOE34 was further separated by a silica gel column chromatography, eluting with $n$-hexane-EtOAc $(4: 1)$ to give $2,4,5$-trimethoxydalbergiquinol $(10 \mathrm{mg})$. The structure of this compound was elucidated through comparison of the ${ }^{11} \mathrm{H}$ - and ${ }^{13} \mathrm{C}$-NMR spectral data with those of the literature. ${ }^{42}$ 
a

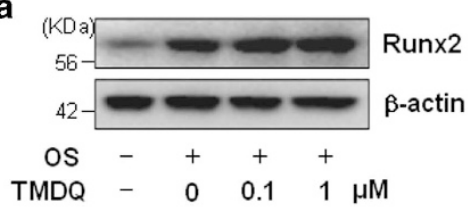

b

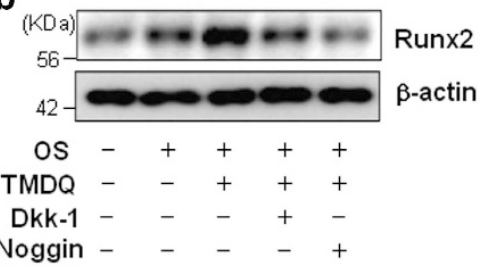

C

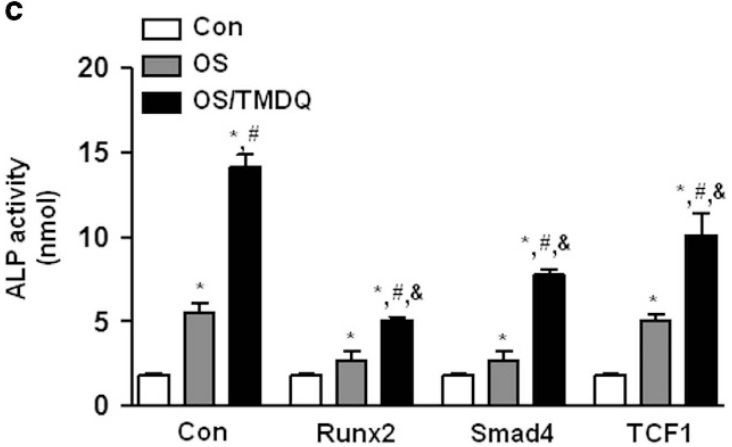

Figure 6 Involvement of Runx2 on TMDQ-induced BMP- and Wnt/ $\beta$-catenin pathways in the osteoblasts. (a) Cells were cultured in OS with the indicated concentration of TMDQ for 2 days, and then the expression of Runx2 was determined by western blot analysis. (b) Effects of inhibitors for BMP- and Wnt $\beta$-catenin on TMDQ-induced Runx2 expression. Cells were pretreated with a BMP inhibitor, noggin $(10 \mu \mathrm{g} / \mathrm{ml})$, or a Wnt $\beta$-catenin inhibitor, DKK1 $(0.5 \mu \mathrm{g} / \mathrm{ml})$, for $1 \mathrm{~h}$, and then cultured in OS with TMDQ for 2 days. The expression of Runx2 was assessed by western blot analysis (b). (c) $24 \mathrm{~h}$ after transfection with Runx2, Smad4, and TCF1 siRNAs, cells were cultured in OS with TMDQ for 5 days. ALP activity was measured ${ }^{\star} P<0.05$, versus control. ${ }^{\#} P<0.05$, versus $\mathrm{OS} .{ }^{\&} P<0.05$, versus TMDQ. Data are representative of three independent experiments
4,5-Trimethoxydalbergiquinol: yellow amorphous powder. ${ }^{1} \mathrm{H}-\mathrm{NMR}\left(\mathrm{CDCl}_{3}, 400 \mathrm{MHz}\right)$ $\delta 5.15$ (dt, 1.6, 10.4, H-2a), 4.87 (dt, 1.6,16.8, H-2b), 6.26 (ddd, 6.4, 10.4, 17.2, $\mathrm{H}-3$ ), 5.04 (br d, 6.4, H-4), 6.70 (s, H-5), 6.63 (s, H-8), 7.11-7.24 (H-2', 3', 4', 5', $\left.6^{\prime}\right), 3.69\left(\mathrm{~s}, 6-\right.$ and $\left.7-\mathrm{OCH}_{3}\right), 3.82\left(\mathrm{~s}, 9-\mathrm{OCH}_{3}\right) .{ }^{13} \mathrm{C}-\mathrm{NMR}\left(\mathrm{CD}_{3} \mathrm{OD}, 100 \mathrm{MHz}\right)$ 111.16 (C-2), 141.98 (C-3), 48.66 (C-4), 115.86 (C-5), 144.76 (C-6), 150.00 (C-7), 99.8 (C-8), 153.1 (C-9), 124.9 (C-10), $144.2\left(\mathrm{C}-1^{\prime}\right), 129.0\left(\mathrm{C}-2^{\prime}, 6^{\prime}\right), 129.5\left(\mathrm{C}-3^{\prime}, 5^{\prime}\right)$, 126.9 (C-4'), $56.7\left(6-\mathrm{OCH}_{3}\right), 56.9\left(7-\mathrm{OCH}_{3}\right), 57.6\left(9-\mathrm{OCH}_{3}\right)$.

Primary culture of mouse calvarial osteoblasts. Primary osteoblasts were isolated from calvariae of 1-day-old ICR mice after dissected aseptically and treated with $0.2 \%$ collagenase-dispase enzyme solution (Sigma-Aldrich, St. Louis, MO, USA). Cells (passage 0 ) were collected by centrifuge after repeated digestions and cultured in $\alpha$-minimum essential medium without L-ascorbic acid supplemented with $10 \%$ fetal bovine serum, penicillin $(100 \mathrm{U} / \mathrm{ml})$, and streptomycin $(100 \mu \mathrm{g} / \mathrm{ml})$ at $37{ }^{\circ} \mathrm{C}$ in a humidified atmosphere of $5 \% \mathrm{CO}_{2}$ and $95 \%$ air. The cells were detached and reseeded at $\sim 70-80 \%$ confluence, and then the cells (passage 1 ) were used for the experiments reported here. To test the effects of TMDQ on osteoblast differentiation, osteoblastic differentiation was induced by changing OS medium containing $50 \mu \mathrm{g} / \mathrm{ml}$ L-ascorbic acid and $10 \mathrm{mM} \beta$-glycerophosphate when the cells are $\sim 80 \%$ confluent. The recombinant noggin and DKK1 were purchased from Invitrogen (Carlsbad, CA, USA; Catalog Number: PHC1506) and PeproTech (Rocky Hill, NJ, USA; Catalog Number: 120-30), respectively. The medium was replaced every 2 days during the incubation period. TMDQ was dissolved in 100\% DMSO and then diluted it $(1: 1000)$ directly into the medium. Final concentration of $0.1 \%$ DMSO was used as the vehicle control. For siRNA transfection, cells were transfected using Lipofectamine RNAiMAX according to the manufacturer's specification (Invitrogen).

MTT assay. Cell toxicity was measured by an MTT assay to detect NADHdependent dehydrogenase activity. Fifty microliters of MTT solution $(5 \mathrm{mg} / \mathrm{ml})$ in $1 \mathrm{x}$ phosphate-buffered saline (PBS) were directly added to the cells, which was then incubated for $2 \mathrm{~h}$ to allow MTT to metabolize to formazan. Absorbance was measured at a wavelength of $540 \mathrm{~nm}$ using an ELISA reader (Beckman Coulter, Fullerton, CA, USA).

ALP activity. ALP activity was measured by spectrophotometry. Cells were homogenized in $0.5 \mathrm{ml}$ distilled water with a sonicator, and centrifuged. The aliquots of cell homogenate were incubated with $15 \mathrm{~mm} p$-NPP in $0.1 \mathrm{~m}$ glycine- $\mathrm{NaOH}(\mathrm{pH}$ 10.3) at $37^{\circ} \mathrm{C}$ for $30 \mathrm{~min}$. The reaction was stopped by adding $0.25 \mathrm{~N} \mathrm{NaOH}$. The absorbance was measured at $405 \mathrm{~nm}$ using an ELISA reader (Beckman Coulter).

Table 1 RT-PCR primers and conditions

\begin{tabular}{|c|c|c|c|c|}
\hline Genes & Primer sequence $\left(5^{\prime} \rightarrow 3^{\prime}\right)$ & Annealing temp $\left({ }^{\circ} \mathrm{C}\right)$ & Cycle number & Product size (bp) \\
\hline$A L P$ & $\begin{array}{l}\text { F: ACACCTTGACTGTGGTTACTG } \\
\text { R: CCATATAGGATGGCCGTGAAG }\end{array}$ & 58 & 35 & 139 \\
\hline OPN & $\begin{array}{l}\text { F: GAGGTGATAGCTTGGCTTATGG } \\
\text { R: TCCTTAGACTCACCGCTCTT }\end{array}$ & 55 & 30 & 124 \\
\hline OCN & $\begin{array}{l}\text { F: ACACCATGAGGACCATCTTTC } \\
\text { R: CGGAGTCTGTTCACTACCTTATT }\end{array}$ & 55 & 35 & 148 \\
\hline$B S P$ & $\begin{array}{l}\text { F: TGTTTGTAGTGGGCTTCTTCTT } \\
\text { R: TCCATCTAGTCCCAGCTCATAG }\end{array}$ & 55 & 35 & 121 \\
\hline BMP2 & $\begin{array}{l}\text { F: ACACAGCTGGTCACAGATAAG } \\
\text { R: CTTCCGCTGTTTGTGTTTGG }\end{array}$ & 58 & 35 & 109 \\
\hline BMP4 & $\begin{array}{l}\text { F: TGCAGACCCTAGTCAACTCT } \\
\text { R: CACCACCTTGTCATACTCATCC }\end{array}$ & 55 & 28 & 110 \\
\hline Wnt1 & $\begin{array}{l}\text { F: GTTCTGCACGAGTGTCTATGA } \\
\text { R: GGAGAGATGGATCGCTATGAAC }\end{array}$ & 55 & 30 & 145 \\
\hline Wnt3a & $\begin{array}{l}\text { F: AGGTAAGCTACTCCCTCAACTA } \\
\text { R: CTGAAGCACCCTCTCATGTATC }\end{array}$ & 55 & 30 & 115 \\
\hline Wnt5a & $\begin{array}{l}\text { F: AGCCCAGCTGATTCTTAATACC } \\
\text { R: GCTCAACTACATGGGACTTTCT }\end{array}$ & 55 & 30 & 174 \\
\hline Runx2 & $\begin{array}{l}\text { F: ACTCTTCTGGAGCCGTTTATG } \\
\text { R: GTGAATCTGGCCATGTTTGTG }\end{array}$ & 55 & 28 & 103 \\
\hline$\beta$-Actin & $\begin{array}{l}\text { F: AATGTGGCTGAGGACTTTG } \\
\text { R: GGGACTTCCTGTAACCACTTATT }\end{array}$ & 55 & 28 & 109 \\
\hline
\end{tabular}


ALP staining. Cells were washed with $1 \times$ PBS and then fixed in $4 \%$ formaldehyde for $20 \mathrm{~min}$ at room temperature. The cells were rinsed with distilled water, and permeabilized by $0.1 \%$ Triton $\mathrm{X}-100$. Cells were incubated at $37^{\circ} \mathrm{C}$ for $30 \mathrm{~min}$ in the Naphthol-AS-BL alkaline solution mixture (Sigma-Aldrich).

Alizarin red S staining. After 14 days of culture, cells were fixed in $70 \%$ icecold ethanol for $1 \mathrm{~h}$ and rinsed with distilled water. Cells were stained with $40 \mathrm{mM}$ Alizarin Red S (pH 4.2) for 10 min with gentle agitation. The level of Alizarin red S staining was observed under light microscopy. Stains were eluted with $100 \%$ DMSO to quantify the amount of Alizarin red staining and measured at $590 \mathrm{~nm}$.

RT-PCR and quantitative real-time PCR. The total RNA of cells was extracted with Trizol reagent (Life Technologies, Gaithersburg, MD, USA) according to the manufacturer's instructions. One microgram quantity of RNAs isolated from each sample was reverse-transcribed with oligo (dT) ${ }_{15}$ primers with AccuPower RT PreMix (iNtRON Biotechnology, Gyeonggi-do, South Korea). Next, the generated cDNAs were amplified with AccuPower PCR PreMix (Bioneer Corporation, Daejeon, South Korea). The sequences of primers are listed in Table 1. Quantitative real-time PCR was performed using a LightCycler 1.5 Systems (Roche Diagnostics GmbH, Mannheim, Germany). Thermocycling conditions consisted of an initial denaturation of $10 \mathrm{~s}$ at $95^{\circ} \mathrm{C}$, followed by 45 cycles of $95^{\circ} \mathrm{C}$ for $10 \mathrm{~s}, 60^{\circ} \mathrm{C}$ for $5 \mathrm{~s}$, and $72{ }^{\circ} \mathrm{C}$ for $10 \mathrm{~s}$. For the calculation of relative quantification, the $2^{-\Delta \Delta C T}$ formula was used, where $\Delta \Delta C_{T}=\left(C_{T \text {,target }}-C_{T} \beta_{\text {-actin }}\right)$ experimental sample- $\left(C_{T \text {,target }}-C_{\top}, \beta_{\text {-actin }}\right)$ control sample.

Western blot analysis. Cells were washed twice with ice-cold PBS, and lysed in $20 \mathrm{mM}$ Tris- $\mathrm{HCl}$ buffer $(\mathrm{pH} 7.4)$ containing a protease inhibitor mixture $(0.1 \mathrm{mM}$ PMSF, $5 \mathrm{mg} / \mathrm{ml}$ aprotinin, $5 \mathrm{mg} / \mathrm{ml}$ pepstatin A, and $1 \mathrm{mg} / \mathrm{ml}$ chymostatin). Protein concentration was determined by Bradford reagent (Bio-Rad, Hercules, CA, USA). Equal amounts of lysates $(20 \mu \mathrm{g})$ resolved on SDS-polyacrylamide gel electrophoresis were transferred to a polyvinylidene fluoride membrane (Millipore, Bedford, MA, USA), and the membrane was blocked with $1 \times$ TBS containing $0.05 \%$ Tween20 and $5 \%$ skim milk or $2 \%$ BSA for $1 \mathrm{~h}$ at room temperature. After blocking, the membranes were incubated overnight at $4{ }^{\circ} \mathrm{C}$ with the respective primary antibodies as follows: $\beta$-catenin (E247; $1: 1000$, \#ab32572, Abcam, Cambridge, UK), p-ERK1/2 (1:2000, \#9101S, Cell Signaling Technology, Beverly, MA, USA), ERK1/2 (1: 2000, \#9102S, Cell Signaling), p-p38 (1: 1000, \#9211S, Cell Signaling), p38 (1: 1000, \#9212S, Cell Signaling), p-JNK (1:500, \#9251, Cell Signaling), JNK (1:1000, \#9252S, Cell Signaling), GSK3 $\beta$ (D5C5Z; 1:1000, \#12456P, Cell Signaling), p-GSK3 $\beta$ (1:1000, \#9336S, Cell Signaling), Runx2 (O1L7F; 1: 1000, \#12556S, Cell Signaling), p-Smad1/5/8 (D5B10; 1 : 2000, \#13820S, Cell Signaling), Smad1/5/8 (N-18; 1 : 1000, \#sc-6031-R, Santa Cruz Biotechnology, Santa Cruz, CA, USA), $\beta$-actin (C4; $1: 1000$, \#sc-47778, Santa Cruz Biotechnology), Lamin B (C-20; $1: 500$, \#SC-6216, Santa Cruz Biotechnology). The membranes were washed with $1 \times$ PBS and incubated with diluted horseradish peroxidase-conjugated secondary antibodies (1:10,000, Jackson ImmunoResearch, West Grove, PA, USA) for $1 \mathrm{~h}$ at room temperature. After three washes, the membranes were detected using the enhanced chemiluminescence kit (Millipore).

Immunocytochemistry. Cells were grown on glass coverslips and incubated with TMDQ for $48 \mathrm{~h}$. Cells were fixed in $10 \%$ formalin for $15 \mathrm{~min}$ at room temperature. After washing three times in $1 \times$ PBS, the cells were permeabilized with $0.2 \%$ Triton X-100 in $1 \times$ PBS for 20 min, washed three times in $1 \times$ PBS, and then blocked with $5 \% \mathrm{BSA}$ in $1 \times$ PBS for $1 \mathrm{~h}$ at room temperature. After then, the cells were incubated with anti-p-Smad1/5/8 (1:200, Cell Signaling) and anti$\beta$-catenin $(1: 200$, Abcam) antibodies for overnight at room temperature, washed three times, and incubated with Alexa-488-conjugated secondary antibodies ( $1: 500$, Invitrogen) for $2 \mathrm{~h}$ at room temperature. The cells was stained with DAPI (Sigma-Aldrich) and washed three times, mounted on glass slides, and viewed on confocal microscopy (Cell Voyager, Yokohama, Japan).

Statistical analysis. The data were analyzed using the GraphPad Prism version 5 program (GraphPad Software, Inc., San Diego, CA, USA). Data are presented as mean \pm S.E.M. Satistical significance was performed on the data using one-way analysis of variance and the differences were assessed by the Dunnett's test. A value of $P<0.05$ was considered to be statistically significant.

\section{Conflict of Interest}

The authors declare no conflict of interest.
Acknowledgements. This work was supported by the National Research Foundation of Korea (NRF) grant funded by the Korea government (MEST; No, 2012R1A5A2051384)

1. Marie PJ, Kassem M. Osteoblasts in osteoporosis: past, emerging, and future anabolic targets. Eur J Endocrinol 2011; 165: 1-10.

2. Riggs BL, Parfitt AM. Drugs used to treat osteoporosis: the critical need for a uniform nomenclature based on their action on bone remodeling. $J$ Bone Miner Res 2005; 20 : 177-184.

3. Riggs BL, Hartmann LC. Selective estrogen-receptor modulators - mechanisms of action and application to clinical practice. N Engl J Med 2003; 348: 618-629.

4. Augustine M, Horwitz MJ. Parathyroid hormone and parathyroid hormone-related protein analogs as therapies for osteoporosis. Curr Osteoporos Rep 2013; 11: 400-406.

5. Lee DS, Kim KS, Ko W, Li B, Keo S, Jeong GS et al. The neoflavonoid latifolin isolated from $\mathrm{MeOH}$ extract of Dalbergia odorifera attenuates inflammatory responses by inhibiting NF-kappaB activation via Nrf2-mediated heme oxygenase-1 expression. Phytother Res 2014; 28: 1216-1223.

6. Lee C, Lee JW, Jin Q, Jang DS, Lee SJ, Lee D et al. Inhibitory constituents of the heartwood of Dalbergia odorifera on nitric oxide production in RAW 264.7 macrophages. Bioorg Med Chem Lett 2013; 23: 4263-4266.

7. Lee DS, Jeong GS. Arylbenzofuran isolated from Dalbergia odorifera suppresses lipopolysaccharide-induced mouse BV2 microglial cell activation, which protects mouse hippocampal HT22 cells death from neuroinflammation-mediated toxicity. Eur J Pharmacol 2014; 728: 1-8.

8. Wang J, Jiang W, Wang Y. [Anti-inflammation of flavonoid compounds from Dalbergia odorifera T. Chen in lipopolysaccharide stimulated RAW264.7 macrophages]. Xi Bao Yu Fen Zi Mian Yi Xue Za Zhi 2013; 29: 681-684.

9. Zhao X, Mei W, Gong M, Zuo W, Bai H, Dai H. Antibacterial activity of the flavonoids from Dalbergia odorifera on Ralstonia solanacearum. Molecules 2011; 16: 9775-9782.

10. An RB, Jeong GS, Kim YC. Flavonoids from the heartwood of Dalbergia odorifera and their protective effect on glutamate-induced oxidative injury in HT22 cells. Chem Pharm Bull (Tokyo) 2008; 56: 1722-1724.

11. Lee DS, Li B, Im NK, Kim YC, Jeong GS. 4,2',5'-Trihydroxy-4'-methoxychalcone from Dalbergia odorifera exhibits anti-inflammatory properties by inducing heme oxygenase-1 in murine macrophages. Int Immunopharmacol 2013; 16: 114-121.

12. Harris SE, Guo D, Harris MA, Krishnaswamy A, Lichtler A. Transcriptional regulation of BMP-2 activated genes in osteoblasts using gene expression microarray analysis: role of DIx2 and Dlx5 transcription factors. Front Biosci 2003; 8: s1249-s1265.

13. Zhao M, Harris SE, Horn D, Geng Z, Nishimura R, Mundy GR et al. Bone morphogenetic protein receptor signaling is necessary for normal murine postnatal bone formation. $J$ Cell Biol 2002; 157: 1049-1060.

14. Komori T. Regulation of osteoblast differentiation by Runx2. Adv Exp Med Biol 2010; 658: $43-49$.

15. Lee MK, Lim SW, Yang H, Sung SH, Lee HS, Park MJ et al. Osteoblast differentiation stimulating activity of biflavonoids from Cephalotaxus koreana. Bioorg Med Chem Lett 2006; 16: $2850-2854$.

16. Im NK, Choi JY, Oh H, Kim YC, Jeong GS. 6,4'-Dihydroxy-7-methoxyflavanone inhibits osteoclast differentiation and function. Biol Pharm Bull 2013; 36: 796-801.

17. Kim JY, Cheon YH, Kwak SC, Baek JM, Kim YC, Yoon KH et al. 9-Hydroxy-6,7dimethoxydalbergiquinol inhibits osteoclast differentiation through down-regulation of Akt, c-Fos and NFATc1. Int Immunopharmacol 2014; 20: 213-220.

18. Lee HS, Jung EY, Bae SH, Kwon KH, Kim JM, Suh HJ. Stimulation of osteoblastic differentiation and mineralization in MC3T3-E1 cells by yeast hydrolysate. Phytother Res 2011; 25: 716-723.

19. Kim MB, Song Y, Hwang JK. Kirenol stimulates osteoblast differentiation through activation of the BMP and Wnt/beta-catenin signaling pathways in MC3T3-E1 cells. Fitoterapia 2014; 98: 59-65.

20. Katagiri T, Yamaguchi A, Komaki M, Abe E, Takahashi N, Ikeda T et al. Bone morphogenetic protein-2 converts the differentiation pathway of $\mathrm{C} 2 \mathrm{C} 12$ myoblasts into the osteoblast lineage. J Cell Biol 1994; 127: 1755-1766.

21. Wozney JM, Rosen V, Celeste AJ, Mitsock LM, Whitters MJ, Kriz RW et al. Novel regulators of bone formation: molecular clones and activities. Science 1988; 242: 1528-1534.

22. Jia TL, Wang HZ, Xie LP, Wang XY, Zhang RQ. Daidzein enhances osteoblast growth that may be mediated by increased bone morphogenetic protein (BMP) production. Biochem Pharmacol 2003; 65: 709-715.

23. Kuo PL, Hsu YL, Chang $\mathrm{CH}$, Chang JK. Osthole-mediated cell differentiation through bone morphogenetic protein-2/p38 and extracellular signal-regulated kinase $1 / 2$ pathway in human osteoblast cells. J Pharmacol Exp Ther 2005; 314: 1290-1299.

24. Lo YC, Chang YH, Wei BL, Huang YL, Chiou WF. Betulinic acid stimulates the differentiation and mineralization of osteoblastic MC3T3-E1 cells: involvement of BMP/Runx2 and betacatenin signals. J Agric Food Chem 2010; 58: 6643-6649.

25. Huang RL, Yuan Y, Tu J, Zou GM, Li Q. Opposing TNF-alpha/L-1beta- and BMP-2-activated MAPK signaling pathways converge on Runx2 to regulate BMP-2-induced osteoblastic differentiation. Cell Death Dis 2014; 5: e1187. 
26. Chen G, Deng C, Li YP. TGF-beta and BMP signaling in osteoblast differentiation and bone formation. Int J Biol Sci 2012; 8: 272-288.

27. Krishnan V, Bryant HU, Macdougald OA. Regulation of bone mass by Wnt signaling. J Clin Invest 2006; 116: 1202-1209.

28. Bodine PV, Komm BS. Wnt signaling and osteoblastogenesis. Rev Endocr Metab Disord 2006; 7: 33-39.

29. Qiu W, Andersen TE, Bollerslev J, Mandrup S, Abdallah BM, Kassem M. Patients with high bone mass phenotype exhibit enhanced osteoblast differentiation and inhibition of adipogenesis of human mesenchymal stem cells. J Bone Miner Res 2007; 22: 1720-1731.

30. MacDonald BT, He X. Frizzled and LRP5/6 receptors for Wnt/beta-catenin signaling. Cold Spring Harb Perspect Biol 2012; 4: a007880.

31. Reya T, Clevers H. Wnt signalling in stem cells and cancer. Nature 2005; 434: 843-850.

32. Moon RT, Bowerman B, Boutros M, Perrimon N. The promise and perils of Wnt signaling through beta-catenin. Science 2002; 296: 1644-1646.

33. Lee MH, Kim YJ, Kim HJ, Park HD, Kang AR, Kyung HM et al. BMP-2-induced Runx2 expression is mediated by DIx5, and TGF-beta 1 opposes the BMP-2-induced osteoblast differentiation by suppression of Dlx5 expression. J Biol Chem 2003; 278 : 34387-34394

34. Lee MH, Javed A, Kim HJ, Shin HI, Gutierrez S, Choi JY et al. Transient upregulation of CBFA1 in response to bone morphogenetic protein-2 and transforming growth factor beta1 in $\mathrm{C} 2 \mathrm{C} 12$ myogenic cells coincides with suppression of the myogenic phenotype but is not sufficient for osteoblast differentiation. J Cell Biochem 1999; 73: 114-125.

35. Huang YF, Lin JJ, Lin CH, Su Y, Hung SC. c-Jun N-terminal kinase 1 negatively regulates osteoblastic differentiation induced by BMP2 via phosphorylation of Runx2 at Ser104. J Bone Miner Res 2012; 27: 1093-1105.

36. Chen Y, Whetstone HC, Youn A, Nadesan P, Chow EC, Lin AC et al. Beta-catenin signaling pathway is crucial for bone morphogenetic protein 2 to induce new bone formation. $J$ Biol Chem 2007; 282: 526-533.
37. Zhang R, Oyajobi BO, Harris SE, Chen D, Tsao C, Deng HW et al. Wnt/beta-catenin signaling activates bone morphogenetic protein 2 expression in osteoblasts. Bone 2013; 52: 145-156.

38. Rawadi G, Vayssiere B, Dunn F, Baron R, Roman-Roman S. BMP-2 controls alkaline phosphatase expression and osteoblast mineralization by a Wnt autocrine loop. J Bone Miner Res 2003; 18: 1842-1853.

39. Fukuda T, Kokabu S, Ohte S, Sasanuma H, Kanomata K, Yoneyama K et al. Canonical Wnts and BMPs cooperatively induce osteoblastic differentiation through a GSK3beta-dependent and beta-catenin-independent mechanism. Differentiation 2010; 80: 46-52.

40. Zhang JF, Li G, Chan CY, Meng CL, Lin MC, Chen YC et al. Flavonoids of Herba Epimedii regulate osteogenesis of human mesenchymal stem cells through BMP and Wnt/betacatenin signaling pathway. Mol Cell Endocrinol 2010; 314: 70-74.

41. Rodriguez-Carballo E, Ulsamer A, Susperregui AR, Manzanares-Cespedes C, SanchezGarcia $\mathrm{E}$, Bartrons $\mathrm{R}$ et al. Conserved regulatory motifs in osteogenic gene promoters integrate cooperative effects of canonical Wnt and BMP pathways. J Bone Miner Res 2011; 26: 718-729

42. Kulshresth SK, Mukerjee SK, Seshadri TR. Dalbergiphenol, a new constituent of the heartwood of Dalbergia sissoo. Indian J Chem 1974; 12: 10-14.

(i) Cell Death and Disease is an open-access journal published by Nature Publishing Group. This work is licensed under a Creative Commons Attribution 4.0 International License. The images or other third party material in this article are included in the article's Creative Commons license, unless indicated otherwise in the credit line; if the material is not included under the Creative Commons license, users will need to obtain permission from the license holder to reproduce the material. To view a copy of this license, visit http://creativecommons.org/licenses/by/4.0/ 